\title{
Glossophobic Experience Amongst MPSPC Philippines Pre-service Teachers Through Oral Speech Presentations
}

\author{
Jonnelle Fagsao \& Julie Grace Mi-ing \\ Mountain Province State Polytechnic College, Bontoc, Philippines \\ jonnellefagsao@gmail.com
}

\begin{abstract}
ARTICLE HISTORY
Received : 7 December 2020

Revised : 14 December 2020

Accepted : 24 February 2021
\end{abstract}

\section{KEYWORDS}

Oral Communication Learning Public Speaking

Language Communication Skills Speaking Anxiety

Glossophobia

\begin{abstract}
Most individuals are not born to be public speakers; they are educated to be developed as one. When they are in front of an audience being the focus of attention, they experience emotions leading to nausea and excessive sweating because of fear and anxiety. Individuals who have a fear of speaking in public suffer from strong fear in social performance situations and social spheres, which is known as glossophobia. This research aims to discover the different factors that cause speaking anxiety among the pre-service teachers of Mountain Province State Polytechnic College - Teacher Education Department (MPSPC-TED) in Philippines and to suggest strategies that could help prevent them from having glossophobia problem. Samples of interview output, coding, and careful analysis and interpretation of the gathered data from the selected 50 undergraduate students who had research oral presentations, oral lesson demonstrations, and oral speaking presentations have been transcribed and found out major themes that cause glossophobia problems, i.e., linguistic obstacles, audience's manifestation, mastery of the topic and particular motives. Knowing what causes these problems, this study proposed the DISRUPT strategy to reduce students' public speaking anxiety effectively.
\end{abstract}

\section{Introduction}

"The success of your presentation will be judged not by the knowledge you send but by what the listener receives." - Lilly Walters

From the beginning of modern civilization, many people have been overwhelmed with an assortment of often unbearable fears and anxieties (glossophobia) about communicating with others especially in a public performance setting. Glossophobia, also known as speech anxiety is the feeling of fear the researchers witnessed from students when speaking in front of their classmates, often characterised as a fear of speaking publicly or nervousness in communication. There was an obvious feeling of panic among them like breathing rates, over-rapid reactions, trembling of muscles, and slurring of voices among others. Glossophobia, as Ali \& Nagar (2013) defined, is a Greek originated word, with 'glosso' meaning tongue, and 'phobia' meaning threat or fear. Public speaking fear is reflected as a type of dread in the society that causes unembellished avoidance of speaking in front of the people due to fear of discomfort or even degradation. This fear is considered a type of social phobia having great social importance, people with public speaking fear face great difficulty in pursuing their career goals and promotion, and this may cause frustration, depression, and distress in their personality (Perveen, Hasan, \& Aleemi, 2018). However, glossophobia, along with presentation nervousness, communication uneasiness, stage fright, or fear of negative inference is characterised under social anxiety (Dellah et al., 2020). Moreover, people should need to understand that they are not the only ones who may be going through these kinds of emotions; in fact, practically every speaker feels the same (Derin \& Hamuddin, 2019; Derin et al., 2020). It is important that people knowingly comprehend the fact that there are more anxious speakers in the world than those who are not.

The study aims to identify what causes MPSPC preservice teachers' glossophobia problems and by doing so, helping these students by allowing them to be careful of the reasons that cause their problems because an improved understanding of the indications may be important for strategies action, and standardise the glossophobic problems. Since this study came up with causes of speaking anxiety and suggested strategies that could help pre-service teachers of the Bachelor in Elementary Education (BEED) and Bachelor in Secondary Education (BSED) programs to overcome glossophobia, its manifold importance to Mountain Province State Polytechnic College - Teacher Education Department (MPSPC-TED) instructors is how the findings may give tips for inculcating knowledge-based activities to provide skilled-based activities in oral speaking. For the TED instructors who are handling subjects with oral speaking, the findings may provide information about factors that cause speaking anxiety and should include oral intensive communication training for students to boost their interests and abilities in public speaking. 
The status of MPSPC pre-service teachers along with the factors that cause their glossophobic problems were assessed as bases for strategies suggested to help them prevent from having such problems. As future educators, the researchers want to help in the prevention and elimination of glossophobia problems amongst pre-service teachers of MPSP.

\section{Literature Review}

Many researchers have identified anxiety or fear of speaking as an important type of social phobia that affects performance. Individuals who are afraid of speaking openly face numerous challenges in following their career goals and found a limited measure for promotions, which is an indication of extensive individual agony, dissatisfaction, and gloominess as confirmed by Pertaub et al. (2002, p. 68). Approximately $21 \%$ of respondents from a survey of Ruscio et al. (2008) suffer from tremendous glossophobia problem and reason for such great miseries or evasions. People with this problem are incapable to establish their skills in diverse social circumstances, they feel uncomfortable and not only have fear of mistaken estimation by others but also humiliation. Although they know that this fear is baseless but they suffer from severe anxiety in the feared situation, in turn, they always stay away from the situation in speaking publicly (Pertaub et al., 2002).

Speaking is an interactive and complex process of constructing meaning that involves producing, receiving, and processing the information as mentioned by Brown (1994) as well as Burns and Joyce (1997). However, Burns and Joyce (1997), considered that speaking's forms and meanings are still dependent on the context in which it occurs, that includes the participants and their collective experiences, also the physical environment, and the purpose of speaking. Cited from Perveen et al. (2018), Strahan (2003) explored that very unsatisfactory grades in studies also are the outcome of public speaking fear among students, relatively in overcoming this fear, they escape to be familiar to these circumstances, eventually, and this fear is a problem in the students' career chance which might involve public speaking.

The mastery of a public speaking skill is a priority for every teacher because speaking can be regarded as the mode of communication which is mostly used to express opinions, transmit information, and make impressions on others as cited from Busbus (2015). It is the process of building and sharing meaning through the use of symbols verbally and non-verbally. Fluency in English speaking is important to minimize the speaking phobia. Students should have fluency in this language to communicate in classroom discussion; though Filipinos are known to be prominent in
ESL, it is quite alarming that there is already a decrease of competence in the English language oral skills among students nowadays as reported by Orbeta and San Jose (2013).

Research confirms that pressure of risk of public embarrassment has long been recognized as sources of unproductive tension among many students. Referring to Busbus (2017) and Fagsao (2019), there were indications of an increase in the prevalence of depression, anxiety, and stress among students in colleges and universities that includes categories of students who are deployed as student interns, students having oral research defense, and students complying for the requirement of the subject in oral communication skills. Concerning this, it is very obvious that glossophobia is the major problem that instructors are concerned about, that is why researches related to this study are being conducted year in year out in every college and university.

\section{Method}

Given the overwhelming amount of literature exists and the various dimensions and factors being studied, this qualitative research made use of phenomenological design. Creswell and Creswell (2018) describes the phenomenological study as the common meaning for several individuals of their lived experiences of a concept or a phenomenon. This design aims to elucidate the meaning and structure as well as the essence of the lived experiences of the students around this specific phenomenon. With this, personal interviews and actual observations as data collection documents, equal in-depth information, free responses, and flexibility that cannot be attained by other procedures. In this study, the researchers used the phenomenological design to analyse the lived experiences of pre-service teachers in MPSPC in terms of glossophobia in the classroom.

The pre-service teachers were considered appropriate participants for this study as they are the future educators of tomorrow (Table 1). The interview was conducted during the SY 2018-2019 at the Teacher Education Department, MPSPC-Bontoc Campus, Bontoc, Mountain Province, Philippines.

The key instrument of data collection consists of interview guides based on priori codes which would also validate the interview questions as well as the interview results on such questions about glossophobic problems in oral skills presentation and the causes of their fear and anxiety regarding the oral presentation. Another key instrument is the face-to-face interview exploring and discovering the participants' feelings towards glossophobia while doing the oral skills action. 
Table 1. Distribution of BEED-BSED Respondents

\begin{tabular}{lccll}
\hline \multicolumn{1}{c}{ Course } & \multicolumn{2}{c}{ Gender } & & Subject \\
\cline { 2 - 3 } & Male & Female & \\
\hline BSED- Social Studies & 2 & 5 & Research in Social Studies \\
BSED-English & 6 & 7 & Language Research \\
BSED-Math & 1 & 1 & Research in Mathematics \\
BSED-Science & 0 & 1 & Research in Science \\
BSED-English & 5 & 9 & Speech and Stage Arts/ Oral communication \\
BEED & 2 & 6 & Practice Teaching \\
BSED-English & 2 & 6 & Practice Teaching \\
& 18 & 32 & \\
\hline Total & $\mathbf{5 0}$ & & \\
\hline
\end{tabular}

The following procedures in the conduct of this study were sequentially followed: (1) Permission to undergo interviews and observations was obtained by the researchers from the teachers-in-charge, panel of evaluators, and advisers; (2) Permission to undergo an interview was approved by the student and was requested to ensure the confidentiality of their identities. So all the names used in this study are not specified. Sessions of observation took place over the second semester of the SY 2018-2019 (specifically on January 22nd, 24th, and February 5th). The observations involved whole class observations of selected pre-service teachers' actual oral presentations; (3) Some students involved were interviewed in their most appropriate time within the department's classrooms. The BSED interns were interviewed after being observed from their actual teaching demonstrations from respective schools of affiliation. Video-audio from cell phones was used aside from field notes to record every session that transpired during the interview. Answers and opinions were highly appreciated and kept confidential; (4) The results during the interview and observations were transcribed, analysed, coded, and identified. From the results, themes emanated representing the students' glossophobic experiences during the oral presentations.

\section{Results \& Discussion}

After transcription, confirmation, analysis, and coding, the researchers were able to come up with themes that reasoned out their glossophobic problems. This study presents analyses and interprets the findings of the study on the glossophobic problems experienced by the selected preservice teachers of BEED-BSED in MPSPC. As a result, strategies that could help to prevent them from having glossophobia were considered. The researchers' version was presented in the acronym of LAMP referring to Linguistic Barriers, Audience's Manifestation, Mastery of the Topic, and Particular Reasons as adapted from Busbus' (2015) rendition. They are presented in the figure below.

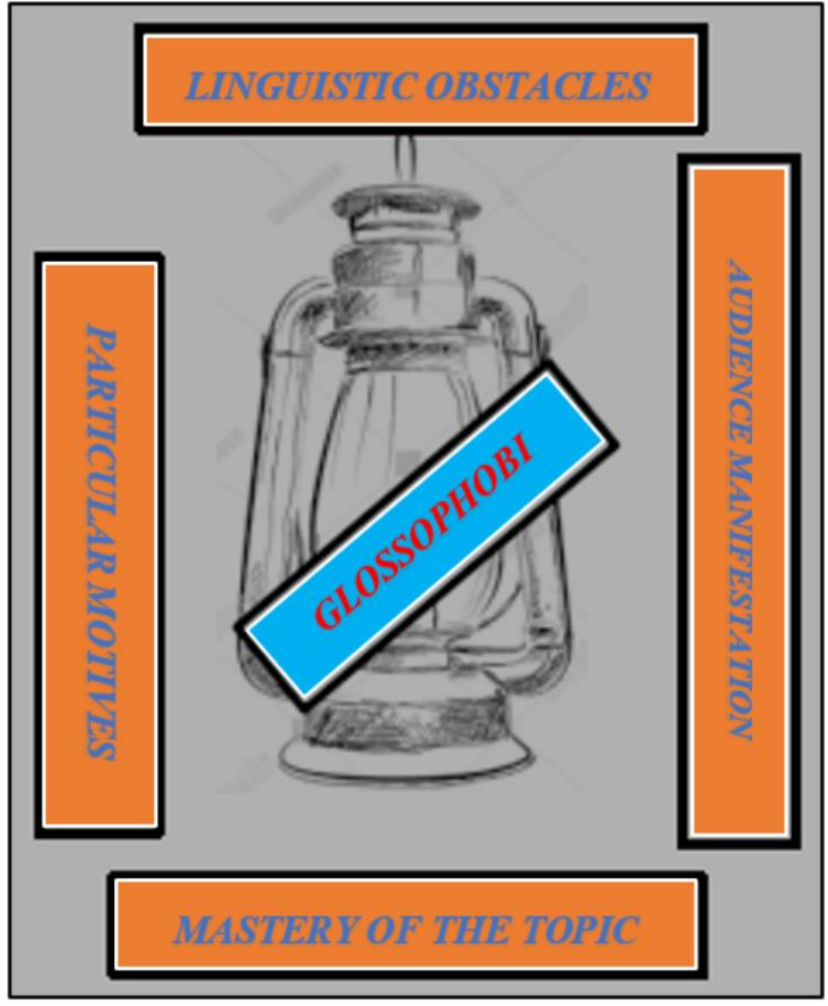

Figure 1. Factors that cause Glossophobia amongst BEED-BSED students in MPSPC

Glossophobia has been studied under three main approaches, namely, an individual's trait, a momentary emotional state, and situation-specific anxiety. The first approach is defined as an "individual's likelihood of becoming anxious in any situation" (Spielberger, 1983, in MacIntyre \& Gardner, 1991, p. 87). This perspective considers anxiety to be a characteristic of the individual's personality, affecting not only language learning but also other situations. The second perspective understands anxiety as "apprehension experienced at a particular 
moment in time, for example, before taking examinations" (Spielberger, 1983, in MacIntyre \& Gardner, 1991, p. 90), and "[It] is interested in the here-and-now experience of anxiety as an emotional state" (MacIntyre \& Gardner, 1991, p. 87). The name of the third approach, "situation-specific anxiety", was coined by MacIntyre and Gardner (as cited in Horwitz, 2001, p. 113) and it refers to the diverse and consistent nature of certain anxieties, e.g. public speaking or participating in class (Ellis, 2008). Glossophobia has also been shown to be heavily influenced by the confidence or self-efficacy that students might have when performing a given task, eventually influencing the academic outcome and language proficiency. With these approaches, the following themes were derived.

\subsection{Linguistic Obstacles}

To date, good communication skills are needed in every walks of life. Raja (2013) mentioned that, "[using] communication through the use of language has developed social harmony, social status, and professional competencies [among men]," (p. 154). Languagecommunication plays a major role in developing a relationship. It can also affect the relationship between teachers and students in any classroom setting. More specially, communication inspires the usefulness of teaching, performance assessment, and the management of discipline problems. It should also be direct even though there are barriers that make it complex, difficult, and frustrating to ensure. Some linguistic barriers of communication common to students in MPSPC are the following: pronunciation, grammar, and vocabulary.

\subsubsection{Pronunciation}

It is important to accept the existence of a type of anxiety specific to the language learning process because it can represent an emotionally and physically uncomfortable experience for some students. Some students majoring in English who were observed possess such pronunciation problems. This problem is commonly called "regional defect" in pronunciation which is common in some places in the local area. It was accepted that this "regional defect" affects expressing such English words while delivering lessons. Ironically, these [pre-service] students are majoring in English that problems regarding pronunciation heighten their glossophobic dilemma. As students expressed their sentiments during the face-to-face session, one laments:

"I am sorry, sir, I know that you are disappointed with my pronunciation...Pronouncing the words during the oral demonstration is difficult for me because of my regional defect. The fact that I am a future English teacher, this is [really] my worst problem that I don't know how to solve. This problem [really] affects my confidence executing y prepared lessons in class especially when I am being observed by somebody such as a critic teacher like you and the principal."

(Interview with a teacher,

Barlig National High School, Barlig, Mt. Province, January 2019)
Another participant made a revelation and expressed (changes on the structure were done by the researchers):

"[...] when I finished my speech as my final examination, the room was unobtrusive. I was so dumb dead when some of my classmates frankly said that, that was my very poor oral performance. Maybe because I felt nervous immediately. Today, I considered that [experience] to be my most traumatic one because obviously, I received very low merit from my teacher."

Interview with a student, Oral Communication Subject, May 2019

As far as this linguistic obstacle is concerned, it is absolutely a common dilemma among students in other places in the hinterlands as cited from Busbus (2015), who made mention Subasi's study in 2010 claiming that the more influential factors leading to high anxiety cover are the attention to intonation and pronunciation, the motivation, and the interference of mother tongue.

\subsubsection{Grammar}

Grammar is one of the most difficult aspects to master particularly for students taking Teacher Education as their chosen course. English grammar has been traditionally viewed as Close (1992) remarked to be "a system of the syntax that decides the order and patterns in which words are arranged in sentences" (13). It is argued, as CelceMurcia (2002, p. 121) stated, that mastering grammar is a difficult procedure that involves "making a series of decisions about when and why to use one form rather than the other". Most students seem to be concerned about making the right decisions when speaking or writing in the second language (L2) that requires grammatical proficiency (Derin et al., 2020).

"[...] when it comes to grammar, I do admit that I am always committing grammatical errors the reason I usually use code-switching in my teaching skills. What matters most is that my students can gradually grasp every lesson I teach to them. So far, even though I was been embarrassed in class with regards to my grammatical errors committed, at least, I can still handle my lesson explanations clearly which is the important one, not my grammar."

(Interview with a Math major pre-service teacher, MPSPC Faculty Room, January 2019)

Vocabulary. Gruneberg \& Sykes (1991) distinguished the two types of vocabulary which are the active and the passive vocabulary. The former type of vocabulary referred to the one that the students had been taught and that they were expected to be able to use. In the meantime, the second one referred to the words which the students would have to recognize when they will meet them, nevertheless they would perhaps not be able to articulate the words. Moreover, Hatch and Brown (1995), indicated two kinds of vocabulary, which he termed as the receptive vocabulary and productive vocabulary. 
The receptive vocabulary is considered as the words that the learners recognize and understand when they are used in context, but which they cannot produce. As Stuart (2008) expressed that this receptive type of vocabulary is what learners recognize when they see or meet in reading a text but do not use it in speaking and writing. Meanwhile, the productive vocabulary is the words that the learners comprehend and can articulate appropriately and use practically in speaking and writing. It contains what is needed for receptive vocabulary plus the capability to speak or write at the appropriate time. Productive vocabulary is an active process, on the other hand, because it is here where the learners can produce the words in expressing their thoughts to others.

"[...] the vocabulary is a crucial aspect of teaching because it pressures me during the lesson when there are words' semantic meaning not clearly given when asked by some students. Limited vocabulary is always a problem because many of us pre-service teachers are not confident about vocabulary teaching and at times do not even know where to begin to form an instructional emphasis on word learning."

(Interview with an English major pre-service teacher, MPGCHS,

January 2019)

A study by Gynan (1989, cited in Young, 1991) investigated the learning practices of students and found that vocabulary is considered the most important practice in language learning, followed by pronunciation. In some other Asian countries, students usually lose confidence when encountering unknown words. Consequently, English teachers have to teach vocabulary before transporting on to interpretation or listening texts. According to Cheng (1997), students of the English majors were found to experience more anxiety than the non-English majors because they expected that as English majors, they should not make grammatical mistakes and should know every word when listening to English. Teachers need to understand for themselves and make it clear to their students that grammar errors can be excused when speaking, and that the effort is better appreciated than staying silent for fear of being perceived incorrect (Nursafira, 2020).

\subsection{Audience's Manifestation}

Weissman (2012) explains why some speakers do speak faster when in front of the audience. According to him, the pressure of the situation stimulates the adrenaline rush which produces time distortion that causes a presenter to experience glossophobia. This experience is commonly observed among the respondents especially when they seem that the presence of a crowd is intimidating towards them. This scenario is akin to "stage fright" and "shyness" in front of people. In this factor, the presence of some students, critic teachers as well as the principals, the panel of evaluators, and advisers are the source of the respondents' glossophobic problems.
One reason that causes a glossophobic problem among the respondents is the thorny issues observed in the classroom. This is the disturbing student's misbehaviours composed of disruptive talking, talking out of turn, being silly, interfering with speaking activities, un-accepted facial expressions, verbal offenses, rudeness to the studentteacher, disobedience, and antagonism.

"[...] there are traditional problems that cause anxiety to me within the room that consists of intolerable behaviours of my students. I had to pay an excellent deal of time and drive to manage the total category. Clearly, students' misbehaviours impede the evenness and quality of my teaching and additionally delay the training within the classroom. I felt embarrassed once I hear some murmuring repetitions of grammatical mistakes I committed. The worst is, I also can witness a number of them sporting some unwanted facial expressions before of me."

(Interview with a particular pre-service teacher, MPGCHS

February 2019)

Most student-interns were interviewed regarding student misbehaviours and they attributed some of these experiences which caused them anxious towards their students. The researchers classified it as talking-out-of-turn. This is another problem behaviour mainly referring to students chatting among themselves on irrelevant teasing remarks towards their teachers.

"[...] if I ask them to refrain from such behaviour, they are rebellious and demand to behave oppositely. They won't listen to me. They are going to insist to try to do what they think... anyway, this can be a challenge to me."

(Interview with a pre-service English teacher, Bachelor in Secondary Education (BSED), January 2019)

Some BSED student-teachers exemplified that disrespect means rudeness, talking back, and agitative lecturers. As equally remarked student-teachers interviewed within the schools of MPGCHS, Sabangan National High School, and Albago National High School in the local area.

"[...] occasionally they are going to argue against us...just because we are only practice teachers."

(Interview with student-teachers, MPGCHS, February 2019)

"[...] some students continually offer inappropriate and extraneous answers to my queries, that is, I asked a thoughtful question however these students gave unacceptable answers with a frown on their faces. If I commented on them, one would be furious and a few would be unreceptive against me."

Interview with student-teachers, MPGCHS, January 2019 
"[...] when contradictory, students are typical with poor approaches, particularly the boys in the class. Later, I would scold at them, and they would become argumentative $[\ldots]$ "

Interview with student-teachers, MPGCHS, January 2019

"[...] more seriously, they would express their resentment by murmuring such unacceptable sounds. But this situation was not quite always."

Interview with student-teachers, MPGCHS,

January 2019

Some BEED pre-service teachers added that some of the aforementioned problematic behaviours, which were a common occurrence among students, whether they were elementary pupils or university students (Syahdan et al., 2017). A pre-service teacher deployed in Bontoc Central School mentioned that:

"...some pupils had problems in getting along with their classmates. When other classmates had wrong answers, they would immediately call out and point out their mistakes. This in reality somewhat affected the total class."

Interview with pre-service teacher,

BCS,

February 2019

Among several audience behaviours that cause glossophobia reported, relatively some students pointed out that "having disturbing chat" was the most common and the most disruptive factor when defending one's research thesis. A pre-service teacher explained that:

"[...] gossiping during my presentation affects me most... it alters the oral presentation setting atmosphere as well as oral presentation progress. Even there were few spectators in the presentation room, their low voice can cause anxiety to me."

Interview by the researchers, MPGCHS, January 2019

Another problem that causes glossophobia is "shyness" which differs importantly from individual to individual, and from situation to situation. This type of problem occurs in cases where learners lack established communication skills in speaking towards the audience. For instance, in a teacher-researchers perception of "shyness" experience, he expressed that:
"[...] the most problem I can't fix. No matter how and what I do, when shyness appears I cannot voice out what is inside me. I tremble when I know that I'm going to speak in front of people."

\section{Interview with a student-teachers, TED Faculty Room, March 2019}

\subsection{Mastery of the Topic}

This refers to the depth of understanding regarding the students' knowledge or skill. Glossophobia occurs when there is a problem of a lack of mastery towards the topic within a certain speaker. Moreover, when there is a lack of mastery, there is a lack of confidence in preparation and delivery. Among the students observed, this is the most mutual cause of their glossophobic problems because many of them have a submissive nature and they tend to feel uncomfortable while speaking in front of others. As was observed during an oral research paper defense, lack of preparation in the students' presentations did contribute to activating their glossophobic fear. These findings are supported when one of the evaluators encouraged the researchers to be heartened first in their initial phase of presentation [that is on preparation] so that they could be stimulated to defend their research study orally in an oral defense session. When asked why from the pre-service teachers/researchers about the matter, one of the oral presenters answered (edited by the researchers):

\begin{abstract}
"[...] it is well obvious that my delivery is extremely dissatisfactory to the panel members. If I were to rate myself, I will say that the dearth of preparation created me intimate with anxiety. I simply solely browse what was within the PPT while not maintaining direct contact and my rate of speech was too soft and monotonous"
\end{abstract}

Interview with BSED-SS student MPSPC, Room 302, March 2019

The comment of one of the panel member is supported by the suggestion of Songsiri (2007) saying that if students are encouraged and are facilitated with various strategies for the accomplishment of their goals at their own pace, not only develop, regain and repose confidence, but also become autonomous and lifelong learners.

\subsection{Particular Motives}

This refers to glossophobia experienced by the respondents which were caused by their being. Each respondent gave their personal opinions related to the causes of glossophobia within themselves. Throughout the personal interviews, the researchers found out common responses from them which are related to this theme are podium panic and shame.

As we learned that everyone can experience podium panics and shame related to stage fright, speech anxiety, or talking terror. This is what one experiences before or during 
oral speaking in front of an audience. Out of the 50 respondents, most of them claim about the matter. As a result, a student in Language Research revealed that (edited by the researchers):

"[...] stage fright may be a common feeling experienced by anybody particularly if it's your first time to be exposed in a very crowd. I mean this is often common once one was designated to defend one's analysis. I recommend that solely those that did a significant impact within the analysis manuscript are the one to speak orally to avoid worry and anxiety."

Interview with a language research student, MPGCHS, March 2019

The student's revelation could be made by reasons of having stage frights and shame because of committing grammatical errors, lacking strategic styles in presentations, having regional accents and colloquialism, and discomfort with your one's physical appearance. These would cause negative impacts such as being laughed at for the mistakes and make verbal or non-verbal reactions to the part of the respondents, especially in the English language class.

Aside from podium panic and shame, there are other reasons for glossophobia as gathered from personal interviews among the students: (a) self-consciousness in front of large groups. This is the most frequently named reason for performance anxiety; (b) concern that others are judging them; (c) past failures and embarrassments; and (d) poor or insufficient preparation. Studenst, especially student teachers, must confront their problems in speaking as they have the immediate responsibility and expectation to teach other students to speak well (Nahliah \& Rahman, 2018).

The factors analysed to affect the ability of the students in oral communication skills. Although there are other factors observed during the observations, the researcher limited his focus only on the major factors to give such remedies to address the common problems. From further experiences as a language teacher, the researchers suggested some strategies that would help solve the glossophobic problems and this would be the acronym DISRUPT.

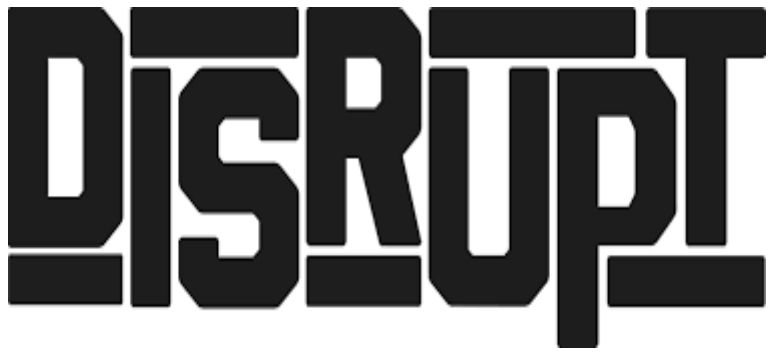

Figure 2. The Acronym for the Strategies Suggested Stopping Glossophobia among MPSPC Pre-Service Teachers
Disrupt means to stop (Figure 2). This research proves that fear of public speaking is a learned skill and can be overcome by practicing and rehearsing before presentations. The following strategies can help the students as oral speakers overcome public speaking anxiety:

a. Diaphragmatic breathing practice should be learned. It will help reduce and release the contradiction in the solar plexus associated with fear and anxiety. It also helps to relax the speech so nobody doesn't look anxious obviously.

b. Involve the listeners. Research indicates empathy or a feeling of mutual support between speakers and listeners is the surest relief from stage fright. Once a speaker receives that first positive reaction from an audience, he will suddenly feel much more confident and relaxed.

c. Seek feedback from the audience during practice sessions or can ask someone to record the talk. Viewing it several times for self-criticism also helps enable the learning and development process. The speakers should expect audience responses and questions that may be produced during preparation so that they could have confidence.

d. Recognise and acknowledge success. It may not have been perfect, but chances are that one is far more critical of himself than the audience is.

e. Understanding the topic eliminates the chance of making a mistake or getting off track during a public speaking activity. A moment of silence is nothing to be afraid of. If a speaker loses track of what he is saying or begins to feel nervous, likely, the audience will not mind a pause to consider what he has been saying. Practicing complete speech several times would certainly give an edge. Speakers can practice it with a small number of people they are at ease with.

f. Prepare, Practice, Prepare. Clearly, if a speaker prepares his topic carefully, he will greatly reduce his concern about what he is going to say. A speaker should prepare effectively and feels more like he is ready to speak. His ideas will be firmly set in his mind. Preparation and practice will help any speaker confident for nothing beats preparation.

g. Take Time to use the right joke at the right time. Humour helps with this. Every audience will appreciate a speaker's honesty and will be drawn to him for it.

\section{Conclusion}

To summarise, the study was able to successfully determine the causes of glossophobia among the pre-service teacher students involved and these are: (a) linguistic obstacles, (b) audience's manifestations, (c) mastery of the topic, and (d) practical motives (LAMP). Basing on their comments and revelations during the interviews, the results show that audience manifestations are considered to be the primary ones. Although facing the audience itself can 
obviously cause these respondents to experience grave glossophobic problems, this study contributed by uncovering more specific themes that caused speaking anxiety. Audience's manifestation is followed by linguistic obstacles that intensify their pressure in speaking in front of the English language as the medium of communication, considering that most of what was observed and interviewed was from the English major class. The third factor is the practical motives which consist of their personal experiences on stage frights and shame. The last factor that contributes to the glossophobic problems of the students is the mastery of the topic which depends on their knowledge about a certain topic.

Another significant contribution of this study is the practical strategy the researchers developed based on the findings of this study named DISRUPT, which stands for Diaphragmatic breathing practice, Involve the listeners, eek feedback, Recognise success, Understand topic, Prepare topic, and Take time. The researchers recommend future researchers to formulate similar research regarding the factors which cause communication and public speaking anxiety to better prepare student teachers in adapting with their role to teach their own students to communicate and speak in public with confidence.

\section{References}

Ali, N., \& Nagar, R. (2013). To study the effectiveness of occupational therapy intervention in the management of fear of public speaking in school going children aged between 12-17 years. The Indian Journal of Occupational Therapy, 45(3), 21-25.

Bootzin, R. R., \& Richard R. (1991). Psychology Today: An introduction. McGraw-Hill.

Burns, A., \& Joyce, H. (1997). Focus on speaking. National Center for English Language Teaching and Research.

Busbus, S. L. (2015). Speaking anxiety of ESL pre-service teachers. School of Teacher Education. Saint Louis University.

Celce-Murcia, M. (2002). Why it makes sense to teach grammar in context and through discourse. New perspectives on grammar teaching in second language classrooms, 119-134.

Cheng, Y. S. (2002). Factors associated with foreign language writing anxiety. Foreign language annals, 35(6), 647-656.

Close, R.A. (1982). English as a foreign language. George Allen and Unwin.

Creswell, J. W., \& Creswell, J. D. (2018). Research design: Qualitative, quantitative, and mixed methods approaches. Sage publications.
Dellah, N. F., Zabidin, N., Nordin, N. A., Amanah, F. H., \& Atan, M. A. (2020). Glossophobia: Evaluating University Students' Speaking Anxiety in English Oral Presentations. Jurnal ILMI, 10(1), 116-126.

Derin, T., \& Hamuddin, B. (2019). Foreign Language Classroom Anxiety, and Enjoyment During Study Abroad: A Review of Selected Paper. Lisan: Jurnal Bahasa dan Linguistik, 8(2), 76-82.

Derin, T., Nursafira, M. S., Yudar, R. S., Gowasa, N. S., \& Hamuddin, B. (2020). Persuasive Communication: What Do Existing Literature Tells Us About Persuasive Communication Among Students? Utamax: Journal of Ultimate Research and Trends in Education, 2(1), 12-18.

Fagsao, J. D. (2019). Selected Lyrics of Bontok's "Antoway, Ayoweng, and Chag-Ay" Songs: An Initial Stylistic Assessment. Multidisciplinary Scientific Journal, 2(3), 276-299.

Gruneberg, M., \& Sykes, R. (1991). Individual differences and attitudes to the keyword method of foreign language learning. Language Learning Journal, 4(1), 60-62.

Hatch, E. \& Brown, C. (1995). Vocabulary, Semantics, and Language Education. Cambridge University Press.

Horwitz, E. K. (2001). Language anxiety and achievement. Annual review of applied linguistics, 21, 112-126.

MacIntyre, P. D., \& Gardner, R. C. (1991). Methods and results in the study of anxiety and language learning: A review of the literature. Language Learning, 4, 85117.

Nahliah, ', \& Rahman, F. (2018). Glossophobia in Training of Speech. ELS Journal on Interdisciplinary Studies in Humanities, 1(1), 28-36. https://doi.org/10.34050/els-jish.v1i1.4076

Nursafira, M. S. (2020). TED Talks in EFL Context: An Alternative Way for Teaching and Improving Student's Speaking Skills. ELSYA: Journal of English Language Studies, 2(2), 43-47.

Orbeta, E. D., \& San Jose, A. E. (2013). Apprehension in language learning anxiety as significant correlate of oral performance in English of college freshmen. International Association of Multidisciplinary Research, 5, 155-164.

Pertaub, D. P., Slater, M., \& Barker, C. (2002). An experiment on public speaking anxiety in response to three different types of virtual audience. Presence: Teleoperators \& Virtual Environments, 11(1), 68-78.

Perveen, K., Hasan, Y., \& Aleemi, A. R. (2018). Glossophobia: The Fear of Public Speaking in Female and Male Students of University of Karachi. Pakistan Journal of Gender Studies, 16(1), 57-70. 
Ruscio, A. M., Brown, T. A., Chiu, W. T. \& Sareen, J. (2008). Social Fears and Social Phobia in the USA: Results from the National Comorbidity Survey Replication. Psychological Medicine, 38, 15-28.

Songsiri, M. (2007). An action research study of promoting students' confidence in speaking English. Unpublished doctoral thesis. Victoria University, Australia.

http://citeseerx.ist.psu.edu/viewdoc/download?doi=1 0.1.1.632.176\&rep=rep $1 \&$ type $=$ pdf

Spielberger, C. D. (1983). Manual for the State-Trait Anxiety Inventory (Form Y). Consulting Psychologists Press.

Stuart, W. (2008). Receptive and productive vocabulary size of L2 learners. Studies in Second Language Acquisition, 30(1), 79-95.

Subasi, G. (2010). What are the main sources of Turkish EFL students' anxiety in oral practice? http://files.eric.ed.gov/fulltext/ED537842.pdf

Syahdan, S., Kasriyati, D., \& Andriani, R. (2017). Analisis Kesopanan Berbahasa terhadap Kemampuan Tindak Tutur Mahasiswa. Lectura: Jurnal Pendidikan, 8(2).

Thornbury, S. (2000). How to teach grammar. Pearson ESL.

Weissman, J. (2012, February). When presenting, remember to pause. https://hbr.org/2012/02/whenpresenting-remember-to-pa

Young, D. J. (1991). Creating a low-anxiety classroom environment: What does language anxiety research suggest? The Modern Language Journal, 75, 426439. 